\title{
La Ineficacia del Negocio Jurídico
}

En nuestro país, el Código Civil no establece una regulación orgánica acerca de la ineficacia del negocio jurídico. En su lugar, nuestra legislación propone un tratamiento poco organizado y en ocasiones contradictorio en la regulación de diversos casos específicos de ineficacia. Por tal motivo, en el presente artículo, Alfredo Soria realiza un análisis sobre la ineficacia del negocio jurídico.

Árbitro del Centro de Arbitraje de la PUCP. Árbitro del Centro de Arbitraje del OSCE. Profesor de Contratos en las Facultades de Derecho de la Pontificia Universidad Católica del Perú (PUCP), la Universidad Peruana de Ciencias Aplicadas (UPC), la Universidad Nacional Mayor de San Marcos (UNMSM) y la Universidad del Pacífico (UP). Egresado de la Maestría en Derecho de la Empresa PUCP. Estudios de Postgrado en la Universidad de Buenos Aires.

** El presente artículo fue realizado con la colaboración de la señorita Nicole Allemant Castañeda, alumna de la Facultad de Derecho de la Universidad Peruana de Ciencias Aplicadas (UPC). 


\section{La Ineficacia del Negocio Jurídico}

\section{Introducción}

Cuando se realiza un negocio jurídico ${ }^{1}$ se espera que el mismo tenga efectos y cumpla su finalidad propia. Por ello, en palabras de Zanoni "Todo acto jurídico posee, desde la perspectiva del deber ser, la finalidad- causa final- de producir ciertos y determinados efectos y en ello residirá, precisamente su eficacia. Es decir que por eficacia del acto jurídico debemos entender la aptitud que se predica de él para alcanzar sus efectos propios"2.

Pese a lo enunciado, existen diversos supuestos en los que el negocio jurídico no tendrá los efectos jurídicos inicialmente planteados o simplemente no tendrá efecto alguno. Estos precisamente son los escenarios de la ineficacia del negocio jurídico. Los supuestos de ineficacia del negocio jurídico se presentan porque el negocio jurídico evidencia una deficiencia estructural o porque, aun formado perfectamente el negocio, éste presenta ciertas circunstancias extrínsecas que inciden de manera total o parcial en sus efectos. Es que en realidad, como lo sostiene Cifuentes, "La ineficacia no es una definición, un concepto, sino una consecuencia de aquellos tipos de irregularidades o anormalidades del negocio jurídico"s.

En nuestro país, el Código Civil no establece una regulación orgánica acerca de la ineficacia. En su lugar, nuestra legislación propone un tratamiento poco organizado y en ocasiones contradictorio en la regulación de diversos casos específicos de ineficacia, razón que nos ha motivado a escribir unas breves líneas al respecto.

\section{Ineficacia}

La ineficacia de un acto jurídico no se reduce a la mera falta de producción de los efectos pretendidos al celebrar el contrato, sino que, un acto es ineficaz porque carece de virtualidad para configurar idóneamente una determinada relación jurídica, o porque aun cuando ha configurado esa relación idóneamente, ésta deja de constituir una regulación de los intereses prácticos que determinaron a los sujetos a concluir el negocio. Por ello, se reconoce en nuestra doctrina que existen "dos tipos de ineficacias; a saber: la ineficacia inicial u originaria (denominada también ineficacia por causa intrínseca o ineficacia estructural) y la ineficacia sobreviniente o funcional

1 Nos referimos a cualquier negocio jurídico, como contraer matrimonio, otorgar un testamento, celebrar un contrato de donación o celebrar un contrato de compraventa, entre otros.

2 Zannoni, Eduardo, Ineficacia y nulidad de los actos jurídicos, Editorial Astrea de Alfredo y Ricardo Depalma, Buenos Aires, 1986, p. 124.

3 Cifuentes, Santos, Negocio Jurídico, Editorial Astrea de Alfredo y Ricardo Depalma, segunda edición, Buenos Aires, 2004, p. 709. 
(denominada también por causa extrínseca) ${ }^{\prime \prime 4}$. Desarrollaremos a continuación ambos escenarios de ineficacia.

\subsection{Ineficacia estructural}

En la ineficacia estructural, la imperfección se encuentra en la génesis del acto defectuoso y se vincula con la "ausencia o defecto de los elementos esenciales en el proceso de formación negocial, o mejor dicho, una cuestión de invalidez".

Como lo sostiene Héctor Campos "la invalidez negocial constituye una categoría genérica y descriptiva de todos aquellos escenarios en los cuales se produce una disconformidad de los valores del negocio jurídico con los valores del ordenamiento jurídico, disconformidad que podrá ser resultado de las diversas patologías que incidan sobre la estructura del negocio jurídico"6. En palabras de Rómulo Morales "la invalidez es la irregularidad jurídica del contrato que implica la ineficacia definitiva"7.

Si bien la ineficacia estructural se orienta a tutelar el interés público, sin embargo, las normas también incluyen determinados supuestos en salvaguarda del interés privado. Por ello, la ineficacia estructural se vincula con los supuestos de invalidez efectiva $\left(\right.$ nulidad $^{8}$ ) o de invalidez potencial (anulabilidad ${ }^{9}$ ).

El Código Civil no proporciona una definición acerca de la nulidad o la anulabilidad del acto jurídico. Por ello, es necesario recurrir a la doctrina, la cual utiliza nomenclaturas distintas ${ }^{10}$.

4 Campos García, Héctor Augusto, "Invalidez e ineficacia negocial. Apuntes introductorios para su estudio en el Código Civil Peruano". En: AA.W. El Negocio Jurídico, Lazarte Zabarburú, Marina (Coordinadora), Fundación M.J. Bustamante de la Fuente, Lima, 2014, p. 153.

5 Lohmann Luca de Tena, Juan Guillermo, El Negocio Jurídico. Segunda edición. Editora Jurídica "Grijley", Lima, 1997, p. 516.

6 Campos García, Héctor Augusto, "Invalidez e ineficacia negocial. Apuntes introductorios para su estudio en el Código Civil Peruano". En: AA.W. El Negocio Jurídico. Lazarte Zabarburú, Marina (Coordinadora), Fundación M.J. Bustamante de la Fuente, Lima, 2014, p. 164.

7 Morales Hervias, Rómulo, Estudios sobre Teoría General del Contrato. Grijley, Lima, 2006, p. 530.

$8 \quad$ Artículos $219^{\circ}$ y $220^{\circ}$ del Código Civil.

$9 \quad$ Artículos $221^{\circ}$ y $222^{\circ}$ de Código Civil.

10 La Doctrina Francesa se distingue entre nulidades absolutas (o nulidades de orden público) y nulidades relativas(o anulabilidad), en el Derecho Alemán se contrapone en cambio la nulidad a la impugnabilidad, en el Italiano, la nulidad a la anulabilidad; en el derecho Español, se contrapone la nulidad absoluta- radical o acto nulo, a la anulabilidad. 


\subsubsection{Nulidad}

Todos los supuestos de nulidad ${ }^{11}$ implican una anomalía grave en la estructura del negocio jurídico.

Autores como Edgar Ramírez sostienen que la nulidad es "el grado de invalidez que causa el acto o negocio cuando durante su perfeccionamiento se ha vulnerado el orden público por parte de sus autores"12. Sin embargo, resulta preferible sostener, al igual que Lizardo Taboada, que el acto jurídico nulo es "aquél al que le falta un elemento, un presupuesto, un requisito, o sea contrario al orden público y a las buenas costumbres, o cuando infrinja una norma imperativa"13.

Estos supuestos resultan de tal gravedad, que el ordenamiento ha sancionado la inviabilidad del negocio jurídico en tales circunstancias. Por ello, el acto que se encuentra en un supuesto de nulidad, es ineficaz desde el inicio y perpetuamente. Además, no puede ser confirmado pues no se puede confirmar un acto carente de validez desde el inicio. Es más, como lo sostiene Lizardo Taboada, "tal es la gravedad de la nulidad como sanción del sistema jurídico para los negocios jurídicos defectuosamente conformados o cuyo contenido es ilícito, que la acción judicial para que se declare judicialmente la misma puede interponerla cualquier persona, siempre que acredite legítimo interés para ello, pudiendo solicitarla también el Ministerio

En: Zannoni, Eduardo, Ineficacia y nulidad de los actos jurídicos, Editorial Astrea, Buenos Aires, 1986.

11 En nuestro país, los supuestos o causales de nulidad son descritos en el artículo 219 del Código Civil.

El Artículo 219 del código Civil establece que:

"El acto jurídico es nulo:

1.- Cuando falta la manifestación de voluntad del agente.

2.- Cuando se haya practicado por persona absolutamente incapaz, salvo lo dispuesto en el artículo 1358.

3.- Cuando su objeto es física o jurídicamente imposible o cuando sea indeterminable.

4.- Cuando su fin sea ilícito.

5.- Cuando adolezca de simulación absoluta.

6.- Cuando no revista la forma prescrita bajo sanción de nulidad.

7.- Cuando la ley lo declara nulo.

8.- En el caso del artículo V del Título Preliminar, salvo que la ley establezca sanción diversa".

12 Ramírez Vaquero, Edgar, La ineficacia en el negocio jurídico, Editorial Universidad del Rosario Bogotá, 2008, p. 58-59.

13 Taboada Córdova, Lizardo, Nulidad del Acto Jurídico, Grijley, Segunda edición, Lima, 2004, p. 105. 
Público como defensor de la legalidad, o el juez de oficio, cuando la misma resulte manifiesta"14.

\subsubsection{Anulabilidad}

Como lo sostiene Fernando Vidal "El acto anulable, o sea, el que padece de nulidad relativa, es aquel que reúne los elementos esenciales o requisitos de validez $y$, por lo tanto, es eficaz, pero, por adolecer de un vicio, a pedido de una de las partes, puede devenir nulo"15. Precisamente, la diferencia entre la nulidad y la anulabilidad radica en la magnitud o intensidad de la deficiencia o irregularidad en la estructura del acto y los afectados por los efectos presentes o futuros del mismo. Por ello, Lizardo Taboada ha sostenido que "como la causal de anulabilidad sólo atenta contra el interés privado, afectando a una de las partes que ha celebrado el negocio jurídico, el artículo 222 del Código Civil cuida bien en señalar que la misma se pronunciará a petición de parte y no puede ser alegada por otras personas que aquellas en cuyo beneficio la establece la ley"16. Es decir, la anulabilidad no puede ser alegada por una persona extraña al negocio jurídico, ni declarada de oficio, puesto que solo importa a la parte perjudicada. El acto jurídico anulable tiene necesariamente que ser impugnado, ya que la anulabilidad otorga efectos siempre y cuando su conocimiento o el deber de conocerla se equiparan, es decir cuando la impugnación se produzca, el negocio jurídico se torna nulo. Por ello Werner Flume ha sostenido que "El negocio jurídico anulable es válido hasta que la impugnación tenga lugar. Con la impugnación el negocio jurídico anulable deviene nulo y además ha de considerarse como nulo desde el principio. Frecuentemente, el negocio jurídico anulable se designa como "nulo en situación de dependencia"17.

El artículo 221 del Código Civil establece los supuestos en los que el negocio jurídico es anulable ${ }^{18}$.

14 Taboada Córdova, Lizardo, Negocio jurídico, contrato y responsabilidad civil, Grijley, Lima, 2006, p. 285.

15 Vidal, Fernando, El Acto Jurídico, Editorial Gaceta Jurídica S.A., Novena Edición, Lima, 2013, p. 551.

Taboada Córdova, Lizardo, Negocio jurídico, contrato y responsabilidad civil, Grijley, Lima, 2006, p. 285.

17 Flume, Werner, El negocio Jurídico, Cuarta Edición, Fundación Cultural del Notario, Berlín, 1992, p. 654.

18 El artículo $221^{\circ}$ del Código Civil dispone lo siguiente:

"El Acto jurídico es anulable:

1. Por incapacidad relativa del agente.

2. Por vicio resultante del error, dolo, violencia o intimidación.

3. Por simulación, cuando el acto real que lo contiene perjudica el derecho de tercero. 


\subsection{Ineficacia funcional}

La ineficacia funcional es aquella mediante la cual el acto jurídico constituido posee todos los elementos esenciales, no adolece de ningún vicio de estos, no consta de defectos en su estructura. En palabras de Lizardo Taboada, la ineficacia funcional supone "un negocio jurídico perfectamente estructurado, en el cual han concurrido todos sus elementos, presupuestos y requisitos de orden legal, sólo que dicho negocio jurídico por un evento ajeno a su estructura debe dejar de producir efectos jurídicos (...) los negocios jurídicos tienen también un defecto, pero totalmente ajeno a su estructura, no intrínseco, sino extrínseco"19. Como lo precisa Francisco Moreyra "será causa extrínseca de la ineficacia de un acto jurídico, aquella circunstancia o situaciónya coetánea al nacimiento del acto, ya sobreviniente, pero que no afecta a su proceso de formación ni a sus elementos constitutivos- que determina que un acto que nació válido sea privado momentáneamente de surtir efectos o sea privado posteriormente de continuar produciéndolos. ${ }^{120}$

Si bien existen diversos supuestos de ineficacia funcional, desarrollaremos en el presente artículo, aquellos relativos a la resolución contractual, rescisión, revocación e inoponibilidad. En todos estos supuestos el acto jurídico es válido desde su constitución ya que, posee todos los requisitos esenciales, no obstante, su eficacia se ve afectada por diversas consideraciones jurídicas, extrínsecas a la estructura propia del negocio.

\subsubsection{Resolución}

Como hemos descrito, la ineficacia puede ser funcional, lo que supone un acto jurídico válidamente celebrado, pero que se tornará ineficaz por una causa exterior al negocio. Precisamente, la resolución contractual, es uno de los supuestos de ineficacia funcional. Por ello, el artículo 1371 del Código Civil dispone que "La resolución deja sin efecto un contrato válido por causal sobreviniente a su celebración". Al respecto, Vincenzo Roppo ha señalado que "(...) la resolución afecta no el contrato, sino directamente y solo sus efectos: hace el contrato ineficaz, sin tocar la validez. En otras palabras: la invalidez atañe al contrato como acto; la resolución como relación" 21.

4. Cuando la ley lo declara anulable."

19 Taboada Córdova, Lizardo, Negocio jurídico, contrato y responsabilidad civil, Grijley, Lima, 2006, p. 283.

Moreyra, Francisco, El acto jurídico según el Código Civil peruano, Pontificia Universidad Católica del Perú Fondo Editorial, Lima, 2005, p. 320.

21 Roppo, Vincenzo, "El contrato". En: Gaceta Jurídica, Traducción a cura de Eugenia Ariano Deho, Lima, 2009, p. 859. 
La resolución contractual puede derivar de: (i) la imposibilidad sobreviniente de la prestación $^{22}$; (ii) el incumplimiento contractual ${ }^{23}$ o (iii) la voluntad de las partes ${ }^{24}$.

\subsubsection{Rescisión}

A través de la rescisión se puede dejar sin efecto un contrato por causal existente a su celebración. El acto jurídico está perfectamente constituido pero puede ser declarado ineficaz ya que puede generar algún perjuicio a una de las partes o a un tercero. Esta busca balancear un hecho contractual que se convirtió injusto para alguna de la partes o para algún tercero.

El artículo 1370 del Código Civil recoge la rescisión disponiendo que: "La rescisión deja sin efecto un contrato por causal existente al momento de celebrarlo". Como lo precisa Manuel De la Puente, "entre las teorías de la invalidez y de la ineficacia, el Código se pronuncia por esta últimas, o sea que se considera que el contrato se celebró válidamente, pero por razón de la rescisión queda sin efecto, o sea es ineficaz"25.

Si se bien la rescisión comparte con la anulabilidad que ambas tienen su origen en una causa existente al momento de la celebración del contrato, lo cierto es que se trata de dos figuras distintas. El acto rescindible está válidamente celebrado y no tiene problemas en su estructura, no es un negocio jurídico inválido, pero por previsión

22 Algunos supuestos de resolución de pleno derecho por imposibilidad sobreviniente de la prestación se encuentran previstos en los artículos 1431 y 1432 del Código Civil. Como sostiene Rómulo Morales "sobrevenida la imposibilidad, la resolución opera de pleno derecho, sin necesidad de acto de parte ni de disposición del juez: la sentencia que la pronuncia es declarativa". En: Morales Hervias, Rómulo, Patologías y Remedios del Contrato, Jurista, Lima, 2011, p. 276.

23 Supuestos de resolución contractual derivados del incumplimiento contractual son: la resolución judicial (artículo 1428 del Código Civil), resolución por intimación (artículo 1429 del Código Civil) o la resolución por causal expresa (artículo 1430 del Código Civil). Las referidas normas establecen los mecanismos a través del cual el acreedor podrá ejercer la facultad o dejar sin efecto el contrato ante el incumplimiento de su contraparte. Como sostiene Francisco Moreyra, la resolución por incumplimiento "es una forma de privar de eficacia a un acto jurídico por ocurrir una circunstancia prevista o no por las partes, que se presenta después de su celebración y a la cual la ley o las partes le atribuyen dicho poder". En: Moreyra, Francisco, El acto jurídico según el Código Civil peruano, Pontificia Universidad Católica del Perú Fondo Editorial, Lima, 2005, p. 322.

24 Este es el supuesto del mutuo disenso que, como afirma Manuel de La Puente, tiene "un efecto extintivo, en el sentido que es un contrato que tiene por efecto extinguir un contrato preexistente". En: De la Puente, Manuel, El Contrato en General, Biblioteca para leer el Código Civil, Vol. XI, Primera Parte, Tomo II, Fondo Editorial PUCP, Lima, 1993, p. 194.

De la Puente, Manuel, El Contrato en General, Biblioteca para leer el Código Civil, vol. XI, primera parte, tomo II, Fondo Editorial PUCP, Lima, 1993, p. 176. 
legal, puede tornarse en ineficaz por producir un perjuicio a alguna de las partes o a algún tercero. En cambio, en la anulabilidad, existen problemas estructurales en el negocio jurídico, deficiencias o defectos de los elementos esenciales del acto que pueden ser alegados por la parte afectada quien puede obtener la invalidez del negocio a través de la acción de anulabilidad.

\subsubsection{Revocación}

La revocación es una manera de extinción del negocio jurídico, declarándolo ineficaz, de esta forma, se deja al acto jurídico sin efecto por manifestación de voluntad de una de las partes. Se trata de la ineficacia de un contrato originariamente válido y eficaz. Como lo sostiene Luigi Ferri, la revocación cuenta con las siguientes notas características: "a) es un acto unilateral; b) debe provenir del autor del acto revocado; c) es siempre realizada extrajudicialmente; d) no necesariamente condicionada por circunstancias sobrevenidas o hechos nuevos ${ }^{\prime 26}$.

\subsubsection{Inoponibilidad}

La inoponibilidad implica la ineficacia del acto celebrado respecto de terceros. El negocio jurídico inoponible conserva toda su validez y eficacia entre las partes, es decir, la eficacia del negocio jurídico no es total respecto de todas las personas, pues ciertos terceros pueden desconocerlo como si no existiera. Por ello, Eduardo Zannoni ha sostenido que "(...) en este caso no se trata de un acto válido entre las partes e inválido para ciertos terceros, no está en juego la validez o eficacia estructural del negocio, sino una ineficacia funcional. El acto válido no puede ser inválido a la vez. Pero el acto válido puede incidir "disfuncionalmente" respecto de intereses legítimos ajenos a los sujetos que lo otorgaron"27.

La inoponibilidad se encuentra dentro de la ineficacia funcional, y esta puede ser sobrevenida o existir desde el nacimiento del acto, en consideración a determinados terceros que deciden que les sea inoponible, lo que significa que no son eficaces frente a estos, no los afectan ni los comprometen, pero mantienen su eficacia entre los que lo celebraron y también, frente otros terceros.

Un ejemplo claro de inoponibilidad, en nuestra codificación, es el artículo $161^{\circ}$ del Código Civil que establece "El acto jurídico celebrado por el representante excediendo los límites de las facultades que se le hubiera conferido, o violándolas, es ineficaz con relación al representado, sin perjuicio de las responsabilidades que resulten frente a este y a terceros".

26 Ferri, Luigi, voz, "Revoce in generale, a) Diritto privato". En: Enciclopedia del Diritto, Tomo XI, Giuffré Editore, varese, 1989, p. 198. Citado por: Rómulo. Estudios sobre Teoría General del Contrato, Grijley, Lima, 2006, p. 444-445.

27 Zannoni, Eduardo, Ineficacia y nulidad de los actos jurídicos, Editorial Astrea, Buenos Aires, 1986. 
La inoponibilidad de un acto jurídico es la sanción legal que consiste en declarar válido y eficaz entre las partes, al acto jurídico celebrado, pero ineficaz frente a ciertos terceros. Es decir, el negocio jurídico inoponible no produce efectos frente a terceros, que desconocen el acto jurídico y por tanto, no los afecta -en los casos que la ley lo permita- con el fin de protegerlos. Como sostiene Santos Cifuentes, los terceros "pueden oponerse a que el negocio sea eficiente o productor de efectos a su respecto"28.

\section{A modo de conclusión}

Si bien todo acto inválido es ineficaz, no todo acto ineficaz es inválido. La ineficacia y la invalidez son dos categorías jurídicas distintas. Podría decirse que la ineficacia es el gran género y la invalidez uno de los supuestos de dicho género. Por ello, resulta importante destacar que existen muchos otros supuestos de ineficacia que no implican invalidez o deficiencia alguna en la estructura del negocio jurídico. Esto último alude a los distintos supuestos de ineficacia funcional que son aquellos en los que, habiéndose suscrito contratos válidos, los mismos pueden devenir en ineficaces por diversas consideraciones jurídicas que hemos anotado en este breve texto que pretende delinear un esquema básico y de fácil entendimiento, sobre este importante tema.

28 Cifuentes, Santos, Negocio Jurídico, Editorial Astrea de Alfredo y Ricardo Depalma, segunda edición, Buenos Aires, 2004, p. 714. 